\title{
Assentamentos rurais e as possíveis relações com as dinâmicas de desmatamento na Amazônia: uma revisão sistemática
}

Para melhor contemplar e entender a relação existente entre desmatamento no norte do Mato Grosso e sua relação com os assentamentos presentes na região, o objetivo deste texto foi apresentar uma revisão sistemática da literatura sobre assentamentos rurais e possíveis relações com as dinâmicas de desmatamento na Amazônia, pontualmente buscando responder aos questionamentos: 1). Quais os autores têm mais influenciado os estudos na área (até os dias atuais)? 2). Quais periódicos têm dado destaque ao assunto? e 3). Qual o estado da arte na discussão? Para tal, foi escolhida a base de dados SCOPUS para consulta, através da combinação de diferentes palavras chaves relacionadas ao assunto. Os resultados apontaram que os autores que se dedicam ao tema estão no eixo entre Europa, EUA e Brasil e que o assunto se prolifera através de quatro principais periódicos que primam pela interdisciplinaridade e por isso integram economia, ecologia, gestão florestal, além de estudarem políticas públicas e sistemas socioeconômicos sustentáveis. A revisão aponta três fases distintas do processo de uso e ocupação do solo na região, entretanto, não se pode colocar essas fases em uma sequência linear e descontextualizadas das dinâmicas de mercado, ações políticas e pressões de organizações ambientalistas nacionais e internacionais.

Palavras-chave: Desmatamento; Assentamento; Amazônia.

\section{Rural settlements and the possible relations with the dynamics of deforestation in the Amazon: a systematic review}

\begin{abstract}
To understand the relationship between deforestation in the north of Mato Grosso and settlements, the objective of this paper was to present a literature systematic review on rural settlements and its possible relationship with the dynamics of deforestation in Amazonia, punctually seeking to answer these questions: 1). Which authors have most influenced the studies in the area (until the present day)? 2) Which journals have highlighted the subject ? and 3) What is the current state of the art on the subject.. For this, the SCOPUS database was chosen for consultation, through the combination of different key words related to the subject. The results pointed out that the authors who focus on the theme are between Europe, USA and Brazil and that the subject is proliferated through four main journals that prioritize interdisciplinarity and therefore integrate economics, ecology, forest management, besides studying sustainable policies in socio-economic systems. The review points to three distinct phases of the land use and occupation process in the region. However, these phases can not be placed in a linear and decontextualized sequence of the market dynamics, political actions and national and international environmental organizations pressures.

Keywords: Deforestation; Settlements; Amazônia.
\end{abstract}

Topic: Desenvolvimento, Sustentabilidade e Meio Ambiente.

Reviewed anonymously in the process of blind peer.

Silvia Regina Starling Assad de Avila

Universidade de Brasília, Brasil

http://lattes.cnpq.br/4372044703587699

silassad@gmail.co

Jose Vicente Elias Bernardi

Universidade Estadual Paulista Júlio de Mesquita Filho, Brasil http://lattes.cnpq.br/7324869293866597

bernardi_jve@gmail.com

Antonio Felipe Couto Junior

Universidade de Brasília, Brasil

http://lattes.cnpq.br/1734066833756535

antoniofelipejr@gmail.com

d

DOI: 10.6008/SPC2179-6858.2017.004.0015
Received: 16/07/2017

Approved: 16/10/2017
Mario Lucio de Avila

Universidade de Brasília, Brasil

http://lattes.cnpq.br/9088430726723968

avilaunb@gmail.com

Referencing this:

AVILA, S. R. S. A.; BERNARDI, J. V. E.; COUTO JÚNIOR, A. F.; AVILA, M. Assentamentos rurais e as possíveis relações com as dinâmicas de desmatamento na Amazônia: uma revisão sistemática. Revista IberoAmericana de Ciências Ambientais, v.8, n.4, p.170-188, 2017. DOI: http://doi.org/10.6008/SPC2179-6858.2017.004.0015 


\section{INTRODUÇÃO}

Dados do Programa das Nações Unidas para o Meio Ambiente (PNUMA) alertam que em apenas 13 anos, 50 milhões de hectares de floresta na América Latina foram desmatados, sendo que o Brasil responde por 23 milhões de hectares (PNUMA, 2016). Estudos evidenciam o aumento relativo do desmatamento nos estados de Amazonas (54\%), Acre (47\%) e Pará (41\%) (IPAM, 2016).

Em valores absolutos se observou aumento do desmatamento no Pará $\left(3.025 \mathrm{~km}^{2}\right)$, Mato Grosso $\left(1.508 \mathrm{~km}^{2}\right)$ e Rondônia $\left(1.394 \mathrm{~km}^{2}\right)$, que compreendem em conjunto cerca de $75 \%$ dos desmatamentos registrados. Além disso, esse estudo destaca ainda que as propriedades de até 30 hectares têm sido associadas à $57 \%$ dos registros de desmatamento, o que nos leva a pontuar que o desmatamento deve ser enxergado como sendo um dos mais graves problemas socioambientais, pois além de devastar as florestas e os recursos naturais, pode comprometer aspectos socioeconômicos (ANDRADE et al., 2009).

Esse desmatamento no país apresenta-se como um sistema complexo (BARONA et al., 2010), não podendo ser reduzido por uma determinada variável (GEIST et al., 2001, citado por RIVERO, 2009). Geist et al. (2001) ressaltam ainda que existem interações entre a expansão agrícola, o comércio de madeiras, o crescimento populacional e a construção de estradas. Além disso, incentivos fiscais, colonização, migração, pressão da reforma agraria destacam-se como causas históricas do desmatamento na Amazônia, sendo frequentemente inter-relacionadas (MORAN, 1993). Essas interações geram um modelo de desenvolvimento de grande extensão e baixa produtividade, favorecendo à continuidade do desmatamento e ocasionando uma gama de impactos socioambientais (FEARNSIDE, 2006).

No contexto da Amazônia Legal, por exemplo, entre agosto de 2015 e julho de 2016 foi detectada uma perda de $7.989 \mathrm{~km}^{2}$ de floresta (IPAM, 2017), sendo que o perfil fundiário evidencia que as propriedades privadas são as principais responsáveis pela derrubada da floresta, o equivalente a 35,4\% do registrado, seguidas por assentamentos $(28,6 \%)$ e terras públicas não destinadas mais áreas sem informação cadastral (24\%). Esse processo de desmatamento tem sido mais intenso na floresta de transição que ocorre nos Estados de Mato Grosso e Pará, no ecótono entre a floresta densa e o cerrado (IPAM, 2016). Apenas 62\% dessa floresta encontrada no Mato Grosso ainda permanecem em pé, porém, continuam sendo alvo de desmatamento intenso, já que ocupam as áreas mais aptas para a agropecuária (IPAM, 2016).

Uma das alternativas adotadas para a conservação desses ambientes tem sido baseada na implantação de políticas públicas que visem o estabelecimento de governança em relação à fiscalização e à regulação dos desmatamentos. Um dos exemplos é o estabelecimento de assentamentos, pois quando atendem à legislação ambiental e aos interesses do desenvolvimento sustentável, procedendo o respectivo licenciamento, o cadastro ambiental rural e as demais condicionantes existentes no novo código florestal, já faz dos mesmos, elementos capazes de conter passivos ambientais na região onde se instalam.

Remontando-se ao passado para melhor visualizar a questão, tem-se que as regras da colonização advindas do poder público e a abertura de estradas, destacaram-se na incorporação de novas terras, permitindo melhoria no escoamento da produção (SAYAGO et al., 2004). SAYAGO et al. (2004) ressalta ainda que esse processo induz o produtor, grande ou pequeno, a preconizar a produção agropecuária em 
detrimento da floresta, apresentando-se como um processo de exploração fortemente predatória dos recursos naturais.

Na década de 1970 tem início a discussão sobre o desmatamento na Amazônia, quando se firmou uma cooperação científica internacional por meio do convênio com a Deustche Gesellschaft für Technische Zusammenarbeit (GTZ). Na década seguinte, com a segunda crise do petróleo, o governo passa a rever ações na região, com o objetivo de reduzir as despesas públicas. Os recursos passaram a serem concentrados em áreas especificas, fomentando as exportações da região - a exemplo do projeto Carajás.

No final da década de 1990, este cenário começou a mudar com a implantação de diversos programas e políticas que visavam integrar e proteger os recursos naturais com apoio de investimentos públicos e privados. Um dos primeiros grandes programas implantados pelo governo segundo a série histórica analisada foi o Programa Prevenção e Combate a Desmatamentos, Queimadas e Incêndios Florestais (Florescer) em 2001. Os dados nesta época, mostravam que $76 \%$ dos novos desmatamentos concentravam-se nos estados do Pará, Mato Grosso e Rondônia, seguidos do Tocantins. Essa concentração é justamente na área do Arco do Desmatamento considerada para Becker (2004), uma área onde as atividades econômicas e a estrutura social e política já estavam consolidadas.

Nos anos 2000 tornam-se mais presente estudos que envolvem Amazônia e impactos humanos, a pecuária passa a ser responsabilizada em grande medida pelo desmatamento das grandes áreas. Nesse contexto de conflito, assentamentos rurais podem proporcionar espaços importantes de mediação, tanto por meio parcerias entre organizações sociais organizadas e o Estado, quanto por entidades de apoio e de representação com intuito de reconhecer as demandas dos assentados (MEDEIROS, 1994). Caldart (2000) descreve o assentamento como um lugar social em movimento que vai sendo produzido por meio das relações que ali se estabelecem, e das decisões que são tomadas pelas famílias no processo de organizá-lo e reorganiza-lo permanentemente, a partir das pressões impostas pela realidade.

Além disso, foi observada uma tendência de reversão de desmatamento a partir do momento da valoração econômica da floresta existente nas propriedades rurais, no intuito de conciliar o aumento de renda e a sustentabilidade ambiental (CARPENTIER et al., 2000). Para melhor contemplar e entender a relação existente entre o desmatamento no norte do Mato Grosso e sua relação com os assentamentos presentes na região, o objetivo deste texto foi apresentar uma revisão sistemática da literatura sobre assentamentos rurais e as possíveis relações com as dinâmicas de desmatamento na Amazônia.

\section{METODOLOGIA}

Resultados discrepantes são comuns quando se escolhe estudar um tema, seja qual for. Uma das escolhas, dentre tantas existentes para buscar sanar estes poréns reside na busca de outros estudos 'de melhor qualidade' sobre o assunto. A revisão sistemática de literatura ${ }^{1}$ surge como um novo traçado de pesquisa, que tem como objetivo resumir toda a informação existente sobre um fenômeno de maneira justa

\footnotetext{
${ }^{1}$ Uma das primeiras revisões de que se tem registro data de 1753 na área da saúde e ainda, a primeira soma estatística dos resultados de estudos, técnica hoje conhecida como metanálise, foi publicada em 1904 pelo matemático Karl Pearson.
} 
- ou seja - imparcial, completa e de maneira formal e cautelar. Deve-se apoiar em um plano definido no protocolo da revisão que, dentre outras coisas, estabelece uma sequência bem definida de passos. Devido a essa pormenorização, um de seus pontos positivos reside em permitir que outros pesquisadores possam atualizar a revisão, caso sigam o mesmo conjunto de passos estabelecidos no protocolo. De acordo com Galvão et al. (2004),

A revisão sistemática é uma síntese rigorosa de todas as pesquisas relacionadas com uma questão específica (...) e difere da revisão tradicional, uma vez que busca superar possíveis vieses em todas as etapas, seguindo um método rigoroso de busca e seleção de pesquisas; avaliação da relevância e validade das pesquisas encontradas; coleta, síntese e interpretação dos dados oriundos das pesquisas.

É Mulrow (1994) quem enfatiza que revisões sistemáticas são atividades pouco valorizadas no mundo científico. No entanto, setores como saúde, estudos demográficos e legisladores de políticas públicas necessitam fazer uso de revisão sistemática para integrar e analisar de forma eficiente uma grande quantidade de informação, possibilitando a tomada de decisão mais eficaz. Apesar de a revisão sistemática consumir bastante tempo e recursos, ainda assim é mais rápido e custa menos do que começar um novo estudo completo em uma área que já possui resultados publicados, mas que não foram devidamente explorados (MULROW, 1994).

Para construção desta revisão sistemática de literatura, tomou-se por base a estrutura proposta no Guidelines for Systematic Review in Conservation and Environmental Management (2006). Neste livro de 'diretrizes' são propostas 3 fases na estruturação de uma revisão de qualidade e, dentro destas fases existem ainda subfases que devem ser percorridas.

Quadro 1: Fases na esturação de uma revisão sistemática de literatura de acordo com Guidelines for systematic review in conservation and environmental management.

\begin{tabular}{|l|l|}
\hline \multicolumn{1}{|c|}{ Itens } & \multicolumn{1}{c|}{ Revisão sistemática } \\
\hline Planejando a Revisão & Identificar a necessidade da revisão da literatura; \\
& Definir as questões de pesquisa que se pretende responder com a revisão; \\
& Criar o protocolo da revisão; e \\
& Validar o protocolo. \\
\hline Conduzindo a Revisão & Buscar os estudos primários*; \\
& Selecionar os estudos primários; \\
& Avaliar a qualidade dos estudos primários; \\
& Extrair as informações dos estudos primários e, \\
\hline Escrevendo a Revisão da literatura. & Uealizar a síntese das informações. \\
\hline
\end{tabular}

Legenda: *Esta etapa envolve 3 estratégias: manual - sites e/ou anais de conferências e periódicos; automática - através de strings de busca e snow-balling - quando se analisa a lista de referências dos artigos em busca de novos estudos. Fonte: Pullin et al. (2006).

\section{RESULTADOS}

Com o objetivo de aprofundar o conhecimento sobre o tema, a revisão da literatura foi realizada buscando respostas às seguintes perguntas: Quais os autores têm mais influenciado os estudos na área (até os dias atuais)?; Quais periódicos têm dado destaque ao assunto?; e Qual o estado da arte na discussão entre as possíveis relações existentes entre os assentamentos e as dinâmicas de desmatamento na Amazônia?

\footnotetext{
2 Os estudos individuais que constituem as "entradas" para uma revisão sistemática são intitulados "estudos primários", e a revisão sistemática constitui uma forma de "estudo secundário", afirma Kitchenham (2004).
} 
Optou-se pela base de dados Scopus, por ter uma inteligência na indexação de artigos, por ser interdisciplinar e também por ser uma base de dados que só publica a versão final. A busca foi realizada usando as palavras-chave desmatamento na Amazônia = 'Amazon deforestation', assentamentos rurais = 'rural settlement', assentamentos sustentáveis = 'Sustainable settlements', Brasil = 'Brasil', reforma agrária $=$ 'land reform', cobertura florestal $=$ 'forest cover', agricultores familiar = 'Smallholders' bem como suas combinações (tabela 1). Embora na base de dados Scopus seja possível escolher a área de pesquisa, neste trabalho optou-se por manter 'todas as áreas'. O 's' de Brasil foi substituído por uma interrogação, para que se pudessem alcançar grafias também com z. O período escolhido foi entre 1970 a 2016 e ordenou-se a busca pelos mais citados.

Dos 262 artigos encontrados, 156 foram excluídos por não estarem de fato relacionados ao tema de interesse, o que foi identificado apenas pela leitura do título e, em caso de dúvida, do resumo. Para a análise subsequente, foram obtidos 106 artigos, agrupados em 65 periódicos e 2 revisões em livro que serão objeto da continuidade do estudo.

A continuidade da revisão dos artigos foi realizada em dois passos: Ordenamento por prestígio (Qualis-Capes ${ }^{3}$ ) e indicadores internacionais (IF - impact factor). A escolha foi feita pelo seguinte critério: periódicos A1 e A2 para Ciências Ambientais (Qualis Capes 2013), periódicos A1 e A2 para Interdisciplinar (Qualis Capes 2015) e aqueles que não estando listados com Qualis possuíssem Fator de Impacto ${ }^{4}$ (IF) maior que 4.000 (Quadro 4). A seguir, os 52 resumos publicados pelos 27 principais periódicos foram lidos. Destes, 38 foram escolhidos por estarem diretamente ligados ao tema.

Em se tratando dos periódicos acompanhados na base Scopus, a evolução das publicações ao longo dos últimos anos e de acordo com os artigos escolhidos para leitura indica que se trata de um assunto com crescente interesse científico, havendo um considerável aumento do número de artigos publicados entre 2011 e 2016, pontualmente falando, em 2012 (6 artigos) e em 2015 (7 artigos).

Buscando entender quem atualmente se dedica a construção do conhecimento na área, não houve a identificação de uma concentração em autores específicos mesmo no total de artigos selecionados. Godar et al. (2014) possuía 2 artigos relacionados ao tema e todos foram selecionados para leitura. Já Nepstad et al. (2014) possuía 3 artigos, porém somente 1 foi selecionado.

O aprofundamento nos artigos escolhidos revelou os influenciadores mais presentes através da referência bibliográfica. Os 15 autores mais citados têm acumulado 864 publicações, entre artigos, livros e outros documentos, sendo que foram citados 26.403 vezes. Especificamente, tratando-se dos artigos escolhidos para a leitura deste capitulo, todos os autores influenciaram 2012 novos textos. A tabela abaixo relaciona esses autores bem como o número de obras citadas (pesquisa em 28/05/2017), a quantidade de citações e quantidade de artigos que fez referência a cada um deles.

\footnotetext{
${ }^{3}$ O Qualis-Periódicos é um sistema usado para classificar a produção científica dos programas de pós-graduação no que se refere aos artigos publicados em periódicos científicos. Tal processo foi concebido para atender as necessidades específicas do sistema de avaliação e é baseado nas informações fornecidas por meio do aplicativo Coleta de Dados. Como resultado, disponibiliza uma lista com a classificação dos veículos utilizados pelos programas de pós-graduação para a divulgação da sua produção.

${ }^{4}$ O Fator de Impacto (FI) dos periódicos científicos é um dos instrumentos bibliométricos existentes, e tem como objetivo precípuo aferir a produção científica dos autores, a qualidade das publicações e presuntivamente classificar os periódicos científicos inseridos no JCR do ISI (RUIZ et al., 2009).
} 
Tabela 1: Autores citados e produção referenciada.

\begin{tabular}{|l|c|c|c|c|}
\hline Autor Citado & $\begin{array}{l}\text { No de } \\
\text { publicações }\end{array}$ & $\begin{array}{l}\text { No de citações total } \\
\text { (cited by) }\end{array}$ & $\begin{array}{l}\text { No de artigos influenciados } \\
\text { especificamente pelo texto escolhido }\end{array}$ & $\begin{array}{l}\text { Razão de influência por } \\
\text { publicação }\end{array}$ \\
\hline NEPSTADE, D. & 120 & 7626 & 274 & 2,28 \\
\hline NEPSTADE, D. & 120 & 151 & 156 & 1,3 \\
\hline BARONA, E. & 4 & 155 & 153 & 38,25 \\
\hline WALKER, R. & 76 & 1510 & 124 & 1,63 \\
\hline RODRIGUES, A. & 68 & 6509 & 118 & 2,73 \\
\hline FERRAZ, S. F. B. & 29 & 357 & 71 & 0,25 \\
\hline FEARNSIDE, P. & 208 & 5689 & 52 & 5,62 \\
\hline GODAR, J. & 8 & 101 & 45 & 1,2 \\
\hline BORNER, J. & 35 & 487 & 42 & 4 \\
\hline GODAR, J. & 8 & 101 & 32 & 0,68 \\
\hline PERZ, S. G. & 76 & 1182 & 52 & 0,84 \\
\hline SMITH, N. J. H. & 33 & 479 & 28 & 24 \\
\hline LIMA, M. & 1 & 24 & 24 & 0,35 \\
\hline SILLS, E. O. & 59 & 1202 & 21 & 1,05 \\
\hline $\begin{array}{l}\text { MENTON, M. } \\
\text { C. S. }\end{array}$ & 19 & 830 & $\mathbf{2 0}$ & \\
\hline TOTAL & $\mathbf{8 6 4}$ & $\mathbf{2 6 4 0 3}$ & & \\
\hline
\end{tabular}

Ao criar um índice baseado na razão entre o número de artigos influenciados e a quantidade de publicações de cada autor, encontra-se que alguns autores foram muito efetivos em influenciar a área a partir de um número reduzido de trabalhos (verde). Barona, E.; Godar, J.; e Lima, M. são os principais contribuidores nesse sentido. Observando a coautoria dentre os trabalhos identificados, chegamos à tabela 2, que ilustra as relações entre eles.

Tabela 2: Relação entre autores citados através do número de trabalhos em coautoria (verde escuro $\rightarrow$ relação forte ; vermelho $\rightarrow$ relação fraca ; branco $\rightarrow$ não relacionados).

\begin{tabular}{|c|c|c|c|c|c|c|c|c|c|c|c|c|c|}
\hline & $\begin{array}{c}\text { Nepstade, } \\
\text { D. }\end{array}$ & $\begin{array}{c}\text { Barona, } \\
\text { E. }\end{array}$ & $\begin{array}{l}\text { Walker, } \\
\text { R. }\end{array}$ & $\begin{array}{c}\text { Rodrigues, } \\
\text { A. S. L. }\end{array}$ & $\begin{array}{l}\text { Ferraz, } \\
\text { S. F. B. }\end{array}$ & $\begin{array}{c}\text { Fearnside, } \\
\text { P. }\end{array}$ & $\begin{array}{c}\text { Borner, } \\
\text { J. }\end{array}$ & $\begin{array}{c}\text { Godar, } \\
\text { J. }\end{array}$ & $\begin{array}{c}\text { Perz, S. } \\
\text { G. }\end{array}$ & $\begin{array}{l}\text { Smith, } \\
\text { N. J. H. }\end{array}$ & $\begin{array}{l}\text { Lima, } \\
\text { M. }\end{array}$ & $\begin{array}{c}\text { Sills, E. } \\
\text { O. }\end{array}$ & $\begin{array}{l}\text { Menton, } \\
\text { M. C. S. }\end{array}$ \\
\hline $\begin{array}{l}\text { Nepstade, } \\
\text { D. }\end{array}$ & & & 1 & & & & & & & & & & \\
\hline Barona, E. & & & & & & & & & & & & & \\
\hline Walker, R. & 1 & & & & & & & & 24 & & & & \\
\hline $\begin{array}{l}\text { Rodrigues } \\
\text { A. S. L. }\end{array}$ & & & & & & & & & & & & & \\
\hline $\begin{array}{l}\text { Ferraz, S. } \\
\text { F. B. }\end{array}$ & & & & & & & & & & & & & \\
\hline $\begin{array}{l}\text { Fearnside, } \\
\text { P. }\end{array}$ & & & & & & & & & & & & & \\
\hline Borner, J. & & & & & & & & & & & & & \\
\hline Godar, J. & & & & & & & & & & & & & \\
\hline Perz, S. G. & & & 24 & & & & & & & & & & \\
\hline $\begin{array}{l}\text { Smith, N. } \\
\text { J. H. }\end{array}$ & & & & & & & & & & & & & \\
\hline Lima, M. & & & & & & & & & & & & & \\
\hline Sills, E. O. & & & & & & & 1 & & & & & & \\
\hline $\begin{array}{l}\text { Menton, } \\
\text { M. C. S. }\end{array}$ & & & & & & & & & & & & & \\
\hline
\end{tabular}

Primeiramente, o que se pode salientar é que uma parceria marcante entre os 15 autores escolhidos; foi demonstrada entre Perz, Stephen e Walker, com 24 textos produzidos juntos, nos últimos dez anos. Foram 20 artigos, 2 revisões, 1 capítulo de livro e 1 paper em conferência. A maioria de suas publicações está na área das ciências sociais (16) e no ano de 2007 foi o pico desta publicação conjunta com um montante de cinco textos. Ainda a tabela 02 expõe que os demais autores não costumam escrever juntos. Apenas Walker e Nepstad escreveram o texto Upland agricultural and forestry development in the Amazon: sustenability, 
criticality and resilience em 1996 publicado na Ecological Economics e Sills e Borner, que também possuem uma publicação conjunta denominada Linking forest tenure reform, environmental compliance, and incentives: lessons from red+ initiatives in the Brasilian Amazon, em 2014, publicado na World Development.

Do ponto de vista das principais publicações, há certa fragmentação do tema entre diversas delas. Algum destaque é atingido pelos periódicos Ecological Economics (com 3 artigos e 3 autores diferentes), Ecology and Society, Science, Forest Ecology and Management (todos com 2 artigos publicados cada). A tabela 3 demonstra finalmente a relação existente entre os autores, sua área de atuação bem como a instituição/pais pertencentes.

Tabela 3: Relação existente entre os autores, área de atuação e instituição/pais pertencentes.

\begin{tabular}{|c|c|c|c|}
\hline Autor & Periódico onde publicou & Área de atuação & Instituição pais \\
\hline Barona, E. & Environmental Research Letters & Geoprocessamento & USA \\
\hline Borner, J. & Ecological Economics & $\begin{array}{l}\text { Meio ambiente e recursos } \\
\text { economicos }\end{array}$ & Universidade de Bonn/Alemanha \\
\hline Ferraz, S. F. B. & Forest Ecology and Management & Engenharia Florestal & Esalq/Brasil \\
\hline Fearnside, $\mathrm{P}$. & Acta Amazonica & Ecologia & INPA/Brasil \\
\hline \multirow[t]{2}{*}{ Godar, J. } & Forest Ecology and Management & $\begin{array}{l}\text { geoprocessamento e sistemas } \\
\text { socioecológicos }\end{array}$ & \\
\hline & Proceedings of the National Academy & of Sciences of the USA & $\begin{array}{l}\text { Instituto ambiental de } \\
\text { Estocolmo/suecia }\end{array}$ \\
\hline Lima, M. & Ecology and Society & Biologia da conservação & Unemat/Mato grosso \\
\hline Menton, M. C. S. & Ecology and Society & Socioecologia & $\begin{array}{l}\text { Universidade de Oxford/Inglaterra } \\
\text { Centro de pesquisa de florestas em } \\
\text { Java/Indonésia }\end{array}$ \\
\hline \multirow[t]{2}{*}{ Nepstade, D. } & Conservation Biology & & \\
\hline & Science & Ciência Ambiental & Instituto de inovação da terra/EUA \\
\hline Perz, S. G. & Human Ecology & Ciências Sociais & Universidade da Florida/EUA \\
\hline Rodrigues, A. S. L. & Science & Ciência ambiental & Universidade de Montpellier/França \\
\hline Sills, E. O. & Land use policy & Economia Florestal & $\begin{array}{l}\text { Universidade de Oxford/Inglaterra } \\
\text { Centro de pesquisa de florestas em } \\
\text { Java/Indonésia }\end{array}$ \\
\hline Smith, N. J. H. & Ecological Economics & & Universidade da Florida/EUA \\
\hline Walker, R. & Ecological Economics & Ciências Sociais & Florida State University/EUA \\
\hline
\end{tabular}

Com essa retrospectiva, é possível então responder às perguntas 1 e 2 colocadas inicialmente e delimitar que o tema "possíveis relações existentes entre assentamentos e desmatamento na Amazônia Brasileira" se prolifera através de muitos periódicos, mas recebe especial atenção em 4 deles citados acima, dos quais: 1) a Ecological Economics integra economia à ecologia; a 2) Forest Ecology and Management relaciona ecologia à gestão florestal; a 3) Ecology and Society dedica-se ao estudo de sistemas socioeconômicos sustentáveis; e a 4) Science, uma publicação de descobertas científicas recentes, também conhecida pelas suas publicações sobre política científica e outros assuntos relacionados com a área das ciências e tecnologia. Além disso, as publicações estão na Europa, Brasil e mais recentemente na Ásia.

Sobre o estado da arte na discussão, três fases podem didaticamente contribuir para a compreensão do fenômeno: 1) assentamentos na Amazônia e a subsistência dos agricultores; 2) A expansão da fronteira agrícola e as commodities na floresta e; 3 ) as ações públicas para a contenção do desmatamento e os novos mercados de serviços ambientais. Não são fases totalmente lineares, uma vez que a pesquisa não acompanha a dinâmica real no mesmo ritmo.

A primeira destas fases, tem início com as reflexões em torno da existência ou não da reforma agrária na Amazônia. Para Pasquis et al. (2005) "pode-se afirmar com certeza que nunca houve reforma agrária”(...) 
"o que ocorreu, na verdade, foi um processo de colonização, que paradoxalmente, atraiu a mão-de-obra de excedente de outros estados e favoreceu a concentração fundiária (...)", que favoreceu a concentração de renda, ao mesmo tempo em que favoreceu a expansão do setor agropecuário de grande escala.

O primeiro governo, sendo esse de Fernando Henrique Cardoso, foi o responsável por promover o maior número de assentamentos na Amazônia Legal de todos os tempos: foram mais de 140 mil famílias assentadas na Amazônia neste período, no entanto, sem condições e qualidade para sua subsistência. Em olhar retrospectivo, a primeira onda de colonização da Amazônia brasileira começou na década de 1070, com o Plano Nacional de Integração (PIN) e a construção da Rodovia Transamazônica (MENTON et al., 2009). Como resultado da colonização patrocinada pelo governo, mais de $500.000 \mathrm{~km}^{2}$ da Amazônia brasileira são geridos por famílias de assentamentos (MENTON et al., 2009).

Ao analisarem o processo de ocupação da Amazônia Brasileira por pequenos agricultores, Walker et al. (1996) afirma que a composição demográfica domiciliar e a sua mudança levam os agricultores a se engajarem em diferentes usos de terra durante o ciclo de vida de seus domicílios. Nesse sentido, afirmam que é impossível considerar a sustentabilidade ecológica fora do contexto da sustentabilidade social, envolvendo necessariamente, soluções positivas entre pessoas e grupos sociais e concebem a ideia do ciclo de vida da unidade doméstica, com efeitos sobre padrões de uso e de cobertura da terra, adaptando a teoria do ciclo de vida domiciliar de Chayanov $^{5}$ ao contexto institucional da fronteira agrícola na Região Norte do Brasil. Concluem ainda que, uma vez que os custos da migração de outras regiões do país para a Amazônia são muito altos, eles optam por cultivarem lavouras anuais para garantir a subsistência do grupo familiar, já que este tipo de atividade apresenta a vantagem de requerer uma menor quantidade de terra e capital.

Muitos problemas ambientais da Amazônia vêm sendo creditados aos pequenos produtores de áreas de colonização pela decisão sobre o uso da terra. Este 'ciclo de uso da terra' é refletido pelos indicadores de 'diversidade produtiva' e 'diversidade da paisagem' de acordo com Caviglia et al. (2005). A melhoria deste indicador, por meio da diversificação de atividades nas propriedades, poderia reduzir a demanda por desflorestamento e elevar a oportunidade de custo do trabalho familiar, propiciando suporte financeiro para a intensificação da produtividade agrícola.

Dessa forma, Caviglia et al. (2005) argumentam que os colonos tradicionais da Amazônia: indígenas e descendentes de seringueiros nordestinos têm uma relação sustentável com a natureza devido seu conhecimento sobre os ecossistemas, e que os migrantes do centro sul, praticam suas atividades agrícolas de forma não compatível com o ambiente, sendo, portanto, responsáveis pelas altas taxas de desmatamento da região. Os colonos recentes (constituídos por migrantes do segundo processo migratório), seriam os principais responsáveis pela devastação da floresta ao adotarem um modelo de agricultura incompatível com as características agroecológicas locais.

A importância da Floresta Amazônica, vem sendo citada por diversos pesquisadores ao longo de anos, com destaque para a conservação de sua megabiodiversidade, pelo papel que desempenha e pelos 
riscos assumidos com o quadro de mudanças globais. Considerando sua importância e a pressão sofrida, a Amazônia necessita de modelos de desenvolvimento com atividades econômicas que não presumam o desmatamento exagerado. 0 manejo de recursos florestais, dadas as características e potencialidades da região, se coloca como um dos principais caminhos para se alcançar um desenvolvimento com bases sustentáveis.

Em sintonia com este debate, apresenta-se desde o fim dos anos oitenta, na Amazônia, um grande e justificado interesse em sistemas agroflorestais (SMITH et al., 1996). Os sistemas agroflorestais (SAFs) podem ser definidos como técnicas alternativas que implicam na combinação de espécies florestais com culturas agrícolas, atividades pecuárias ou ambos, cujas combinações podem ser simultâneas ou escalonadas no tempo e espaço. Smith et al. (1996) apresenta como as vantagens destes sistemas: a) os custos de implementação e manutenção podem ser mantidos entre limites aceitáveis pelo produtor, principalmente depois de seu estabelecimento; b) como há diversidade de produção na unidade produtiva; c) diminuem-se os riscos para os produtores, possuem custo de manutenção relativamente baixo por isso podem aumentar a renda do produtor; e d) contribuírem para alimentação da população rural e manterem a capacidade produtiva da terra.

Por isso, os SAFs são promovidos como uma das maneiras ambientalmente adequadas para desenvolver áreas rurais na Amazônia, mas, para que apresentem retorno financeiro no curto prazo, há uma necessidade de expansão do mercado por produtos florestais não madeireiros, com o envolvimento por exemplo, da indústria alimentícia.

Na mesma linha, Caviglia et al. (2005) colocam que a diversificação das atividades com valorização dos produtos chamados alternativos oriundos da reserva florestal ou de culturas perenes, são frequentemente consideradas formas mais sustentáveis, por suprir os serviços ambientais, proteger o solo da erosão, melhorando a sua qualidade por adição de matéria orgânica e fixação de nitrogênio, servindo de micro habitats, e estabilização do ciclo hidrológico e de microclimas.

Mesmo entendendo a importância do manejo florestal no cumprimento da lei, os estudos sobre seu potencial nas comunidades de assentamentos ainda são raros e, neste sentido, Caviglia et al. (2005) buscou examinar o potencial de colheita da madeira através de parcerias empresa-comunidade (CCPs) como meio de aumentar a receita baseada na floresta, sem comprometer o uso doméstico de produtos florestais não madeireiros (PFNMs). Este manejo, se conduzido de maneira racional, além de tornar as florestas rentáveis, em muitos casos mantém sua estrutura e biodiversidade praticamente inalteradas. Neste contexto, Menton et al. (2009), usando a avaliação rural participativa, diários de recursos e questionários domésticos, estudou os impactos dos contratos de captação de informações da CCPs sobre meio de subsistência, incluindo renda doméstica e colheitas de PFNM.

A derrubada da Floresta Amazônica no Brasil produz um crescimento econômico insustentável onde a população pobre atraída para terras recém-desmatadas, não propicio em nada melhoraria de suas condições de vida. Existe um debate a respeito da interpretação dos padrões sociais e econômicos na 
Amazônia Legal onde Rodrigues et al. (2009) encontrou o padrão boom-and-bust ${ }^{6}$ na região ao estudar as variações no nível de desenvolvimento em 286 municípios em diferentes estágios de desmatamento.

Rodrigues et al. (2009) buscou quantificar esse fenômeno com o acompanhamento de diferentes estágios da fronteira (antes do início, no meio da fronteira e depois de ela já ter passado) do desmatamento ao longo de décadas na região (abordagem de fronteiras) através do monitoramento de indicadores-chave de prosperidade - renda, educação e saúde - entre os habitantes das áreas destruídas da Amazônia e colocam que, apesar da ideia de que o desmatamento "é o preço pago pelo desenvolvimento", esse "desenvolvimento é transitório e não resulta em melhoria de bem-estar das pessoas".

Neste estudo, concluem-se que, padrões de vida, alfabetismo e expectativa de vida aumentam com o início do desmatamento, mas declinam com a evolução do desmatamento. Colocam-se ainda que as diferentes relações dos produtores rurais com os mercados e suas respostas por meio da migração, da redução de fecundidade e do ajuste no gerenciamento das culturas agrícolas foram se consolidando gradualmente, transformando a Amazônia numa colagem de domicílios em distintas fases de inserção ao ambiente de pós-fronteira.

Na segunda fase dos estudos, há um maior volume de temas abordados. O problema principal de estudo é a expansão agrícola motivada pela abertura de rodovias para as regiões de floresta e os impactos desta dinâmica de uso da terra. Nessa etapa os assentamentos de reforma agrária, assumem papel significativo no desmatamento.

Durante as últimas duas décadas, as causas do desmatamento mudaram da agricultura de subsistência e programas governamentais de colonização para a agricultura de commodities e produção de madeira centradas na exportação e a atual pressão por expansão de novas áreas de cultivo no mundo (pautada na crescente demanda por produtos amazônicos, como a carne bovina, livre de aftosa e de doenças como a da vaca louca que atingiu a Europa, e a soja, produzida com tecnologia de ponta), poderão gerar um forte desmatamento futuro (NEPSTAD et al., 2006).

Segundo Stickler et al. (2006), a Amazônia é a mais nova fronteira de uma revolução agrícola que é movida pela escassez de terras apropriadas para a expansão da produção agrícola mecanizada nas zonas temperadas, pela adaptação das culturas e dos animais domesticados das zonas temperadas às zonas tropicais, pela redução de barreiras comerciais que permitem que países como o Brasil tirem mais proveito das suas vantagens comparativas.

Ferraz et al. (2005) coloca que o estado de Rondônia (na Amazônia) é marcado por intensos processos de ocupação e conversão de uso da terra desde a década de 1970, que se intensificaram com os projetos de colonização orientados pelo governo federal com apoio do Instituto Nacional de Colonização e Reforma Agrária onde milhares de imigrantes assentaram-se nas terras distribuídas do projeto, resultando em grande perda de floresta nativa e evidenciam que a supressão da vegetação nativa geralmente ocorre em função da incorporação de grandes áreas no processo produtivo, como a agricultura e pecuária. Ferraz et al. (2005)

\footnotetext{
${ }^{6}$ Nos anos 1980, surgiu a hipótese de que o aumento no nível de desenvolvimento com o início das atividades de exploração de recursos naturais nos trópicos seria seguido de uma posterior queda estimulada pela depreciação dos recursos naturais. Este padrão, similar a um $U$ invertido, ficou conhecido como boom-and-bust (MORAN, 1982).
} 
coloca que as principais transformações no uso da terra em Rondônia são ocasionadas pela expansão do pasto e, mais recentemente da soja, que tem acelerado os processos de fragmentação e de perda de floresta no estado de Rondônia. Esse desmatamento se dá principalmente às margens da Rodovia BR-364 pela qual ocorre o escoamento da produção do estado.

A construção da rodovia, por sinal, é reconhecida como elemento determinante para o crescimento dos desmatamentos (TOURRAND et al., 2015). Neste sentido, Perz (2003) publicou na Human Ecology um estudo de caso sobre a Amazônia brasileira e os determinantes sociais e correlatos de uso da terra da adoção de tecnologia agrícola, onde tenta identificar o papel da inovação e diversas tecnologias, no processo de geração de valor no negócio rural e em sua sustentabilidade no longo prazo. $O$ autor busca entender quais os determinantes sociais e quais os correlatos de uso da terra estão ligados a adoção de tecnologias, pelos pequenos proprietários ao longo da rodovia Transamazônica. Os resultados da pesquisa apontaram que as famílias com mais mão-de-obra e capital são mais propensas a adotar tecnologias e que, para todas as tecnologias os "adotantes" tem mais terra "desmarcada" do que os "não adotantes".

Além do exposto, Perz (2003) identificou também que domicílios que se encontram mais distantes dos centros urbanos e que possuem piores condições de acesso têm maior superfície contínua de mata intacta, menor área destinada à agricultura comercial e maior chance de adotar técnicas extensivas de manejo

Godar et al. (2012) aponta que o desmatamento na Amazônia é particularmente severo ao longo das principais estradas de penetração entre as quais a Rodovia Transamazônica (BR-230) é um exemplo emblemático. A agricultura familiar que antes era tida como principal causadora do desmatamento ao longo da rodovia, após anos de pressão econômica e demográfica, teve sua importância diminuída pelo acúmulo de terra em grandes latifúndios destinados à produção bovina, aumentando os distúrbios causados na região (GODAR et al., 2012); por isso, ao buscarem identificar os fatores que explicam o desmatamento a partir da caracterização dos diferentes perfis de produtores colocam capital, tamanho do lote, distância de mercados e força de trabalho como merecedores de destaque.

Para Godar et al. (2012), entender os diversos perfis de produtores ajuda na formulação de políticas públicas capazes de incorporar as especificidades socioeconômicas e ambientais, o que evita visões equivocadamente generalizadas da realidade. Demonstram ainda em seus estudos, a relação entre sistemas produtivos e desmatamento (utilizando a região oeste do Pará como caso), onde produtores voltados à pecuária têm uma contribuição muito mais significativa para o desmatamento do que aqueles que desenvolvem sistemas produtivos mais voltados para a subsistência, ou seja, o desmatamento ocorre de acordo com as condições e necessidades das famílias, expectativas econômicas e sociais, tecnologia e capital disponíveis, localização do lote e acessibilidade, entre outros aspectos.

Seguindo a mesma compreensão do fenômeno, Börner et al. (2007) apontam que a velocidade das transformações e os padrões de ocupação do território amazônico delinearam formas distintas de ocupação do espaço: o ciclo de desmatamento pela agropecuária e extração indiscriminada de madeira e as concentrações concebidas pelos projetos de colonização, distinguidos pela instabilidade, alto grau de evasão 
e fraco desempenho econômico, onde a ocupação do território adquiriu um padrão concentrado ao longo das rodovias. As rodovias associadas as hidrovias e redes de telecomunicações estão alterando a posição econômica da Amazônia.

O crescimento da produção de grãos na Amazônia, principalmente da soja, tem sido apontado como um dos motivos para o aumento das taxas de desmatamento a partir do fim da década de 1990. Esta expansão tem acontecido fundamentalmente em pastagens já formadas, onde o custo de implantação da atividade é menor. No entanto, ao ocupar as pastagens existentes, a soja acaba pressionando a expansão da pecuária para outras áreas de florestas. O estudo de Barona et al. (2010) sugere que a intensificação e expansão de áreas agrícolas no Brasil para as regiões de fronteira teriam causado desmatamento. Os debates em torno dessa questão estão focalizados na premissa de que o desmatamento é ocasionado, principalmente, pela expansão dos cultivos de soja.

Para Barona et al. (2010), o desmatamento que estava sendo impulsionado pela ampliação da pecuária de corte, apresenta agora a soja parece como responsável pela substituição das áreas que anteriormente eram ocupadas pela pecuária. Neste mesmo estudo, salienta-se que o aumento das áreas de soja no Mato Grosso deslocou os pastos para o norte, levando consigo o desmatamento.

Sendo o Brasil o segundo maior produtor de soja do mundo o que se sabe é que a demanda ainda é maior do que a oferta e a cultura da soja cresce de forma acelerada, alterando o contexto do uso do solo no Brasil e em diferentes estados, como por exemplo o estado do Mato Grosso. A cultura ${ }^{7}$ que já ocupa grandes partes do bioma Cerrado, segundo Lima et al. (2001), chega a Amazônia trazendo consigo discussões sobre seus impactos sociais e ambientais.

Lima et al. (2001) se propuseram, então, a estudar o desmatamento relacionado a produção de soja na região conhecida como soy belt envolvendo três regiões de Floresta (Sorriso - no Cerrado, Guarantã do Norte e Alta Floresta - área de transição e Santarém - totalmente localizado no bioma Amazônico) no intuído de perceberem melhor estes impactos na visão dos produtores, de outros agricultores e também na visão dos trabalhadores.

Barona et al. (2010) lembram, ainda, que não há estudos que apresentem ou levem à compreensão sobre os motivadores desta dinâmica, porém é enfática em salientar que a agricultura de larga escala tem sido associado com vasta degradação dos ecossistemas brasileiros, principalmente do Cerrado e da Floresta Amazônica, acarretando na consolidação de terras e o agravando da história de desigualdade na distribuição de terras no Brasil (BARONA et al., 2010).

Segundo dados de Nepstad et al. (2006), a produção de soja em áreas de floresta de terra firme cresceu 15\% ao ano (a.a.) entre 1999 e 2004 . Além disso, ao ocupar áreas de pastagem e terras de pequenos proprietários, a soja "empurra" o gado e os pequenos produtores rurais em direção ao norte, avançando com a ampliação da fronteira agrícola e aumentando a pressão sobre a floresta (NEPSTAD et al., 2006).

\footnotetext{
7 Juntamente com o crescimento do plantio da soja para a alimentação humana e animal, tem ocorrido a comercialização do biodiesel no Brasil e, a espécie, embora não cultivada exclusivamente para a fabricação do biodiesel, acaba tendo praticamente metade de sua produção destinada para a obtenção do mesmo (LIMA et al., 2001).
} 
Não existe apenas uma variável chave ou um único processo capaz de explicar a dinâmica dos desmatamentos na Amazônia. Com relação às causas dos desmatamentos, estas podem estar associadas a variáveis como proximidade de estradas, preço dos produtos agropecuários, disponibilidade de crédito e também ao crescimento populacional, porém estudos como os de Godar et al (2012), têm chamado atenção para o fato de que agricultores familiares desmatam menos do que grandes produtores e, em longo prazo, têm potencial para estabelecer um mosaico de diferentes sistemas produtivos que contribui para a estabilização da paisagem (GODAR et al., 2012). Na terceira fase dos estudos, emergem estudos que apontam para a combinação de ações governamentais e organizações socioambientais com novos mecanismos de mercado.

Fearnside (2006), ao trabalhar a dinâmica do desmatamento, busca descrever seus impactos e salientar algumas formas de controle. Fearnside (2006) relata em seu texto que durante o período de instabilidade econômica no início dos anos 1990, o desmatamento apresentou números relativamente baixos. O pico no desmatamento observado em 1995 deveu-se à retomada da estabilidade e crescimento do consumo interno após a implantação do Plano Real em 1994. Coloca ainda que depois desse pico, o governo federal modificou o Código Florestal, determinando que a área de reserva legal passasse de 50\% para 80\% na Amazônia Legal, o que pode ter reduzido o desmatamento nos anos seguintes. Para Fearnside (2006),

[...] os atores e as forças que conduzem ao desmatamento variam entre partes diferentes da região, e variam ao longo do tempo. Em geral, os grandes e médios fazendeiros respondem pela grande maioria da atividade do desmatamento, mas os pequenos agricultores podem atuar como forças importantes nos lugares onde estão concentrados.

Destaca que "a parte norte do Mato Grosso e muito das partes sul e leste do Pará são dominadas por grandes fazendas de pecuária. Em partes do Pará (tais como focos de desmatamento em Novo Repartimento), pequenos agricultores representam a força principal" (FEARNSIDE, 2006). Como impactos desse desmatamento coloca a perda de serviços ambientais, que têm um valor maior que os usos pouco sustentáveis que substituem a floresta. Estes serviços incluem a manutenção da biodiversidade, da ciclagem de água e dos estoques de carbono que evitam o agravamento do efeito estufa. Retroalimentações entre as mudanças climáticas e a floresta, por meio de processos tais como os incêndios florestais, a mortalidade de árvores por seca e calor e a liberação de estoques de carbono no solo, representam ameaças para o clima, a floresta e a população brasileira.

Ao tratar sobre a questão 'controle' finalmente, coloca que este seria essencial para evitar os impactos da perda de floresta, porém muito do processo do desmatamento está atualmente fora de controle do governo (TORRES, 2005, citado por FEARNSIDE, 2006), e concluem que eventos recentes indicam que o desmatamento pode ser controlado, tendo a vontade política, pois os processos subjacentes dependem de decisões humanas, afinal:

(...) além da repressão ao desmatamento em áreas onde o desmatamento já é bem avançado em propriedades privadas, decisões de governo terão grande efeito sobre a taxa de desmatamento regional quando obras de infraestrutura de transporte forem aprovadas e construídas onde (...) o elemento fundamental para reduzir a velocidade do desmatamento, e um dia pará-lo, é a vontade política para fazer isto. 
Para conservar as florestas, consideram-se que mecanismos de compensação financeira poderiam ser uma boa opção para evitar que o desmatamento siga no ritmo atual além de compensar financeiramente os serviços prestados pela floresta, o que poderia gerar renda para as populações locais, contribuindo para diminuir a pobreza.

Para atuar nesta situação, as experiências de pagamentos por serviços ambientais têm ocorrido em áreas onde ainda existem florestas, especialmente em países da América Latina. No entanto, por ser recente, pouco se conhece acerca dos efeitos da introdução do pagamento sobre o aumento efetivo do fornecimento de serviços ambientais ou das consequências que as mudanças de uso da terra promovidas por ações políticas podem trazer às rendas e ao desenvolvimento das unidades de produção familiar (BÖRNER et al., 2007).

Porém, colocam Börner et al., 2007, que a maioria das transações de pagamentos por serviços ambientais têm sido associados a mudanças no uso da terra em vez do fornecimento direto do serviço fazendo com que os compradores arquem com o risco de que o serviço ambiental não seja fornecido de maneira adequada. Segundo Börner et al. (2007), o valor do pagamento por serviços ambientais deveria permitir que seja superada a barreira de investimentos para adotar mudanças de uso da terra, de maneira a facilitar a transição de sistemas produtivos que ameaçam o fornecimento de serviços ambientais para usos da terra capazes de fornecê-los em maiores níveis.

Uma boa opção seria realizá-los nos estágios iniciais entre as práticas atuais e as práticas incentivadas, a fim de amenizar o período inicial no qual essas práticas impõem custos pesados aos agricultores, permitindo que sejam feitos os investimentos e proporcionando ao agricultor a superação da barreira de investimentos a fim de facilitar a transição para novos sistemas produtivos que serão mais lucrativos no longo prazo (BÖRNER et al., 2007).

Esquemas de pagamentos por serviços ambientais precisam ser parte de estratégias mais amplas para a diminuição da pobreza por exemplo. Nesse sentido, Börner et al. (2007) recomenda que políticas públicas busquem conciliar os objetivos de redução da pobreza e de aumento do fornecimento de serviços ambientais, destacando, contudo, que o conjunto de ações políticas capaz de atingi-los, como incentivos de preço, regulamentação de uso da terra, novas tecnologias, ainda é pouco definido, em parte porque pouco se conhece sobre os fluxos de serviços ambientais e sobre os efeitos que mudanças no uso da terra e no manejo de recursos naturais promovidas por ações políticas alternativas podem ter sobre as rendas das unidades de produção familiar.

Segundo Börner et al. (2007), as políticas econômicas, ambientais e agrícolas, por interferirem nos incentivos e nos limites considerados pelos agricultores, influenciam suas decisões. Nesse sentido, os formuladores de políticas têm procurado modificar os incentivos financeiros para melhorar o fornecimento de serviços ambientais relacionados à agricultura, sobretudo por um mecanismo que, nos últimos anos, tem gerado interesse crescente: o pagamento direto aos agricultores que melhoram o fornecimento de serviços ambientais selecionados ou, simplesmente, pagamento por serviços ambientais (BÖRNER et al., 2007). 
As organizações ambientalistas têm desempenhado um papel importante na região. Novas oportunidades para a preservação surgiram, especialmente nos setores de carne bovina, soja e óleo de palma onde as empresas de commodities que processam e vendem produtos agrícolas in natura bem como os varejistas agora estão mais abertos às demandas de produção livre de desmatamento (NEPSTAD et al., 2006).

Nesse cenário, de acordo com Nepstad et al., 2006, merecem destaque no Brasil do século 21 as iniciativas de ONGs ambientalistas na pressão e negociação com as cadeias produtivas da soja e da carne, com expressivos resultados de redução dos impactos socioambientais ao longo de suas vastas e capilarizadas cadeias produtivas. Nepstad et al. (2006) descreve como um importante avanço de governança ambiental o fato de a International Finance Corporation definir o respeito à legislação ambiental e trabalhista, bem como o uso de apenas agrotóxicos permitidos no país, como condição para a cessão de crédito para sojicultores localizados em regiões do cerrado e da floresta Amazônica.

Diferentes pesquisas colocam o processo do desmatamento na Amazônia Legal associado a fatores de mercado, tais como variações nos preços das commodities agrícolas, bem como às políticas governamentais que incentivam ou combatem esse problema. Porém estudos como Nepstad et al. (2014), indicam que políticas implementadas a partir de 2004 têm contribuído para a redução do desmatamento na Amazônia Legal e apontam que com aplicações de políticas ainda mais consistentes e focadas a partir de 2008, o desmatamento caiu drasticamente. Segundo o estudo, o sucesso brasileiro apoiou-se em 3 estágios de políticas onde:

1) entre 1990 e 2004, estabeleceu-se uma meta ambiciosa das áreas que não poderiam ser desmatadas na região amazônica e $80 \%$ da área de cada propriedade deveriam ser preservados como áreas de Reserva Legal;

2) entre 2005 e 2009, o Governo fez do desmatamento uma prioridade e buscou reforçar seus mecanismos de controle e punição legal, implementando medidas para que diferentes esferas de fiscalização operassem melhor conjuntamente; e

3) 2009, representou um teste ao novo aparato de controle governamental, dado que, após a crise de alimentos de 2008, a soja e outros grãos expandiram-se substancialmente no País.

De acordo com Nepstad et al. (2014), é nesta época ainda que mecanismos de controle social sobre desmatadores surgem e iniciativas como as moratórias da soja e da pecuária excluíram produtores que não respeitavam as leis ambientais e reduziram os incentivos para que estas culturas se expandissem sobre a floresta.

Considerando o histórico de desaceleração nas taxas de desflorestamento desde o nível máximo alcançado em 2004, o constante surgimento de novas áreas desflorestadas e as baixas taxas de reabilitação dessas áreas na Amazônia, revela que o desflorestamento e os impactos negativos associados a ele estão longe de serem controlados.

Godar et al. (2014) passam então a estudar contribuições específicas de atores para a desaceleração na Amazônia brasileira, propondo o cruzamento de dados oficiais do desmatamento, monitorados pelo Inpe, com os setores censitários do IBGE e a partir de então, elaborando um quadro mais detalhado do que está acontecendo e identificando o tipo de propriedade que está ou não desmatando: grandes fazendeiros, assentamentos da reforma agrária, desmatamento ilegal, entre outros. Embora o estudo demonstre que as 
grandes propriedades ainda são as que mais desmatam, os autores destacam agora que porcentagem dos pequenos produtores aumentou.

Godar et al. (2014) coloca que esta mudança se deve ao fato de o governo acompanhar somente os grandes produtores, com sua política de comando e controle uma vez que mais fácil e mais barato mandar a fiscalização para uma grande propriedade que desmata muito do que para vários pequenos produtores que, individualmente, desmatam pouco.

O fato de o desmatamento estar pulverizado aliado a melhorias de infraestrutura, mudança na legislação e moratória da soja, faz necessário que se coloque outras políticas em prática, para evitar os pequenos desmatamentos. Um dos pontos é a governança. A pesquisa identificou que pelo menos $20 \%$ da Amazônia ainda é considerada como 'área remota', sem a presença do Estado. Os resultados do estudo mostram que o governo precisa ampliar sua presença na Amazônia, levando apoio à população local e às empresas para que a economia seja mais eficiente.

Finalmente, a pesquisa coloca a importância de que hajam incentivos para produzir sem desmatar. De acordo com Godar et al. (2014), os mecanismos de incentivos podem trazer benefícios socioambientais para diversos atores, mas principalmente representam uma oportunidade aos pequenos produtores de trilhar um caminho alternativo de desenvolvimento rural. Para Godar et al. (2014), o acesso a oportunidades de pagamentos ou compensações ambientais demanda, além de o reconhecimento das diferentes realidades e necessidades socioeconômicas da região, soluções que conciliem assistência e acesso ao crédito.

\section{CONSIDERAÇÕES FINAIS}

O desmatamento da Floresta Amazônica é um dos principais problemas ambientais do mundo atual, em função de sua grande importância para o meio ambiente. Este desmatamento causa extinção de espécies vegetais e animais, trazendo danos irreparáveis para o ecossistema amazônico e suas principais causas combinam-se entre a degradação provocada pelo corte ilegal de árvores (destinadas ao comércio ilegal de madeira), queimadas ilegais para abertura de pastagens para o gado ou áreas agrícolas (principalmente para a cultura de soja) e os assentamentos humanos (em função do crescimento populacional na região). Como a região é a nova fronteira agrícola do país, as atividades econômicas relacionadas ao espaço agrário vêm tomando destaque no 'quesito desmatamento' resultantes da ocupação de áreas por grandes empresas agropecuárias, produtores e assentamentos de reforma agrária.

A revisão aponta três fases distintas do processo de uso e ocupação do solo na região, entretanto, não se pode colocar essas fases em uma sequência linear e descontextualizadas das dinâmicas de mercado, ações políticas e pressões de organizações ambientalistas nacionais e internacionais. Em um primeiro momento, é pequena a contribuição dos assentamentos para o desmatamento, uma vez que a lógica de subsistência prevalecia e a insuficiência logística impedia as atividades de monoculturas de se estabilizar entre os agricultores familiares. Naquilo que chamamos de fase dois, na literatura revisada, o advento das rodovias é um fenômeno que está diretamente ligado ao desmatamento seja em grandes propriedades ou nos assentamentos. 
Sobre a primeira questão colocada neste capitulo, o que se pode identificar na literatura na relação existente entre desmatamento e assentamentos na Amazônia, é que os assentamentos podem ser sim, responsáveis por parcela significativa do desmatamento (28,8\%) no bioma amazônico (IPAM 2016) e que associação direta entre desmatamento e assentamento ocorre principalmente pela mudança no perfil do tamanho do desmatamento na região, de grande para pequenos polígonos.

Este padrão que tem se repetido dentro dos assentamentos tem impactado as suas taxas anuais de conversão florestal. Pela leitura, o que se evidencia é que a sistemática do desmatamento segue basicamente o mesmo caminho, com a derrubada da floresta em terra pública, a venda da madeira para capitalização, a plantação do capim e alocação do gado e em um segundo momento, as terras de interesse da agricultura dão lugar ao cultivo principalmente da soja. Pode-se inferir também que, o desmatamento tal como é feito atualmente, raramente traz benefícios para a população rural, gerando pobreza e conflitos sociais e agrários.

Entretanto, esse processo de criminalização ambiental dos assentados e assentamentos tem acontecido sem uma análise mais profunda da dinâmica do desmatamento dentro dos mesmos e também sem levar em consideração outros aspectos além daqueles referentes à proporção da área desmatada e o percentual de contribuição anual para a perda de florestas.

A terceira fase dos estudos aponta para governança de políticas e a ação integrada de atores no combate ao desmatamento, mas não revela ainda que o processo tenha se estabilizado ou diminuído. A ausência de ações efetivas de apoio técnico, fomento, fiscalização, controle e incentivos econômicos faz com que grande parte das soluções se localizem mais no plano de intenções e prescrições.

Uma das principais soluções a serem adotadas para a preservação do meio ambiente tem sido direcionada com base na implantação de políticas que visem o desenvolvimento sustentável, assim como o estabelecimento de uma ampla e eficaz governança em relação à fiscalização e à regulação dos desmatamentos. Os assentamentos por exemplo, quando atendem a legislação ambiental e aos interesses do desenvolvimento sustentável (procedendo o respectivo licenciamento, o cadastro ambiental rural e as demais condicionantes existentes no novo código florestal), já faz dos mesmos, elementos capazes de conter passivos ambientais na região onde se instalam.

A leitura realizada para a construção desta revisão sistemática aponta que a tendência de desmatamento pode ser revertida a partir do momento em que se der significado econômico à floresta existente nas propriedades rurais e alternativas sustentáveis podem e devem ser estudadas para conciliar o aumento de renda e a sustentabilidade ambiental. Finalmente, pode-se identificar que desenvolvimento do tema se deu principalmente por um grupo de pesquisadores no eixo entre Europa, EUA e Brasil e recentemente vem se pulverizando em outras geografias com contribuições interessantes na Ásia (especificamente na Indonésia).

Nessa linha, há um conjunto significativo de estudos apontando, desde há muito tempo para a conciliação de uso do solo com relações ecológicas harmônicas ou de baixo impacto, como os sistemas agroflorestais e mais recentemente para a agroecologia. Sobre as outras duas questões colocadas (quem são - e onde estão - os autores e periódicos que merecem destaque sobre esta relação), pode-se chegar à 
conclusão de que o desenvolvimento do tema se deu principalmente por um grupo de pesquisadores no eixo entre Europa, EUA e Brasil e recentemente vem se pulverizando em outras geografias com contribuições interessantes na Ásia (especificamente na Indonésia) e que os periódicos citados navegam em questões relativas principalmente:

a) a integração entre economia e ecologia;

b) ao elo existente entre a ecologia florestal e gestão florestal (com enfoque na aplicação dos conhecimentos biológicos, ecológicos e sociais à gestão e conservação de plantações e florestas naturais);

c) a trabalhos relacionados às bases ecológicas, políticas e sociais para sistemas socioeconômicos sustentáveis envolvendo gestão, administração e uso sustentável de sistemas ecológicos, recursos e diversidade biológica em todos os níveis buscando entender o papel que os sistemas naturais desempenham nos sistemas sociais e políticos; e

d) a cobertura de toda uma gama de disciplinas científicas com publicações importantes investigações científicas originais e de comentários de pesquisas e também notícias, opiniões sobre a política de ciência e outros assuntos de interesse de cientistas voltados a implicações da ciência e da tecnologia.

\section{REFERÊNCIAS}

ANDRADE, D.; ROMEIRO, A.. Serviços ecossistêmicos e sua importância para o sistema econômico e o bem-estar humano. Campinas: UNICAMP, 2009.

BARONA, E.; RAMANKUTTY, N.; HYMAN, G.; COOMES, O. T.. The role of pasture and soybean in deforestation of the Brazilian Amazon. Environmental Research Letters, v.5, p.19, 2010. DOI: https://doi.org/10.1016/i.apgeog.2014.09.003

BECKER, B.. Amazônia: geopolítica na virada do III milênio. Rio de Janeiro: Garamond, 2004.

BÖRNER, J.; MENDOZA, A.; VOSTI, S. A.. Ecosystem services, agriculture, and rural poverty in the Eastern Brazilian Amazon: Interrelationships and policy prescriptions. Ecological Economics, v.64, n.2, p.356-373, 2007. DOI: http://doi.org/10.1016/j.ecolecon.2007.03.001

CALDART, R. S.. Pedagogia do Movimento Sem Terra: escola é mais do que escola. Petrópolis: Editora Vozes, 2000.

CARPENTIER, C. L.; VOSTI, S. A.; WITCOVER, J.. Intensified production systems on the Western Brazilian Amazon settlement farms: could they save the forest?. Agriculture, Ecosystems and Environment, v.82, p.73-88, 2000. DOI: http://doi.org/10.1016/S0167-8809(00)00217-6

CONFORTO, E. C.; AMARAL, D. C.; SILVA, S. L.. Roteiro para Revisão Bibliográfica Sistemática: aplicação no desenvolvimento de produtos e gerenciamento de projetos. In: CONGRESSO BRASILEIRO DE GESTÃO DE DESENVOLVIMENTO DE PRODUTO, 8. Anais. Porto Alegre: UFRGS, 2011.

FEARNSIDE, P.. Desmatamento na Amazônia: dinâmica, impactos e controle. Acta amazônica, v.36, n.3, p.395-400, 2005. DOI: http://doi.org/10.1590/S004459672006000300018

FERRAZ, S. F. B.. Landscape dynamics of Amazonian deforestation between 1984 and 2002 in central Rondônia, Brazil: assessment and future scenarios. Forest Ecology and
Management, v.204, n.1, p.69-85, 2005. DOI: http://doi.org/10.1016/j.foreco.2004.07.073

GALVÃO, C. M.; SAWADA, N. O.; TREVIZAN, M. A.. Revisão sistemática: recurso que proporciona a incorporação das evidências na prática da enfermagem. Revista LatinoAmericana de Enfermagem, v.12, n.3, p.549-56, 2004.

GODAR, J.; GARDER, T.; TIZADO, J.; PACHECO, P.. Actorspecific contributions to the deforestation slowdown in the Brazilian Amazon. Proceedings of the National Academy of Sciences, v.111, n.43, p.15591-155960, 2014.

GODAR, J.; TIZADO, E. J.; POKORNY, B.. Who is responsible for deforestation in the Amazon? A spatially explicit analysis along the Transamazon Highway in Brazil. Forest Ecology and Management, v.267, p.58-73, 2012. DOI: http://doi.org/10.1016/j.foreco.2011.11.046

LIMA, M.; SKUTSCH, M.; COSTA, G.. Deforestation and the social impacts of soy for biodiesel: perspectives of farmers in the South Brazilian Amazon. Ecology and Society, v.16, n.4, 2011. DOI: http://doi.org/10.5751/ES-04366-160404

MEDEIROS, L.. Assentamentos rurais: uma visão multidisciplinar. São Paulo: UNESP, 1994.

MENTON, M.; MERRY, F.; LAWRENCE, A.; BROWN, N.. Company-community logging contracts in Amazonian settlements: impacts on livelihoods and NTFP harvests. Ecology and Society, v.14, n.1, 2009.

MORAN, E. F.. Deforestation and land use in the Brazilian Amazon. Human Ecology, v.21, n.1, p.1-21, 1993. DOI: https://doi.org/10.1007/BF00890069

NEPSTAD, D. C.; STICKLER, C. M.; ALMEIDA, O. T.. Globalization of the Amazon soy and beef industries: opportunities for conservation. Conservation Biology, v.20, n.6, p.1595-1603, 2006. DOI: http://doi.org/10.1111/j.15231739.2006.00510.x 
NEPSTAD, D.; MCGRATH, D.; STICKLER, C.; ALENCAR, A.; AZEVEDO, A.; SWETTE, B.; BEZERRA, T.; DIGIANO, M.; SHIMADA, J.; MOTTA, R. S.; ARMIJO, E.; CASTELLO, L.; BRANDO, P.; HANSEN, M.; MCGRATH-HORN, M.; CARVALHO, O.; HESS, L.. Slowing Amazon deforestation through public policy and interventions in beef and soy supply chains. Science, v.344, n.6188, p.1118-1123, 2014. DOI: http://doi.org/10.1126/science.1248525

PASQUIS, R.; SILVA, A. V.; WEISS, J.; MACHADO, L.. Reforma agrária na Amazônia: balanço e perspectivas. Cadernos de Ciência \& Tecnologia, Brasília, v.22, n.1, p.83-96, 2005.

PERZ, S. G.. Social determinants and land use correlates of agricultural technology adoption in a forest frontier: a case study in the Brazilian Amazon. Human Ecology, v.31, n.1, p.133-165, 2003. DOI: https://doi.org/10.1023/A:1022838325166

PULLIN, A. S.; STEWART, G. B.. Guidelines for systematic review in conservation and environmental management. Conservation Biology, v.20, n.6, p.1647-1656, 2006. DOI: http://doi.org/10.1111/j.1523-1739.2006.00485.x

RIVERO, S.; ALMEIDA, O.; AVILA, S.; OLIVEIRA, W.. Pecuária e desmatamento: uma análise das principais causas diretas do desmatamento na Amazônia. Nova economia, Belo Horizonte, v.19, n.1, p.41-66, 2009.

RODRIGUES, A.; EWERS, R. M.; SOUZA, C. J.; VERISSIMO, A.; BALMFORD, A.. Boom-and-bust development patterns across the Amazon deforestation frontier. Science, v.3245, n.933, p.1435-1437, 2009. DOI:

http://doi.org/10.1126/science.1174002

ROTHER, E.T.. Revisão sistemática x revisão narrativa. Acta Paulista de Enfermagem, São Paulo, v.20, n.2, 2007.

RUIZ, M. A.; GRECO, O. T.; BRAILE, D. M.. Fator de impacto: importância e influência no meio editorial, acadêmico e científico. Revista Brasileira de Hematologia e Hemoterapia, São Paulo, v.31, n.5, p.355-360, 2009. SAYAGO, D.; TOURRAND, J. F.; BURSZTYN, M.. Amazônia: cenas e cenários. Brasília: Editora UnB, 2004.

SILLS, E. O.; CAVIGLIA-HARRIS, J. L.. Evolution of the Amazonian frontier: Land values in Rondônia, Brazil. Land Use Policy, v.26, n.1, p.55-67, 2009.

SMITH, N.; FALESI, Í.; ALVIM, P.; SERRÃO, E.. Agroforestry trajectories among smallholders in the Brazilian Amazon: innovation and resiliency in pioneer and older settled areas. Ecological Economics, v.18, n.1, p.15-27, 1996.

VEIGA, J.; TOURRAND, J.; PIKETTY, M.; ALVES, A.. Três décadas da vida dos colonos em Uruará - PA na rodovia Transamazônica, Brasil. IN: WOOD, C.; TOURRAND, J.; TONI, F.. Pecuária, uso da terra e desmatamento na Amazônia: um estudo comparativo do Brasil, Equador e do Peru. Brasília: Editora UnB, 2015.

WALKER, R.; HOMMA, A. K. O.. Land use and land cover dynamics in the Brazilian Amazon: an overview. Ecological Economics, v.18, n.1, p.67-80, 1996. DOI: http://doi.org/10.1016/0921-8009(96)00033-X 